\title{
Nanopyramid Structure for Ultrathin c-Si Tandem Solar Cells
}

\author{
Guijun Li,* He Li, Jacob Y. L. Ho, Man Wong, and Hoi Sing Kwok
}

State Key Lab on Advanced Displays and Optoelectronics, Department of Electronic and Computer Engineering, Hong Kong University of Science and Technology, Clear Water Bay, Kowloon, Hong Kong

Supporting Information

ABSTRACT: Recently, ultrathin crystalline silicon solar cells have gained tremendous interest because they are deemed to dramatically reduce material usage. However, the resulting conversion efficiency is still limited by the incomplete light absorption in such ultrathin devices. In this letter, we propose ultrathin a-Si/c-Si tandem solar cells with an efficient light trapping design, where a nanopyramid structure is introduced between the top and bottom cells. The superior light harvesting results in a $48 \%$ and $35 \%$ remarkable improvement of the short-circuit current density for the top and
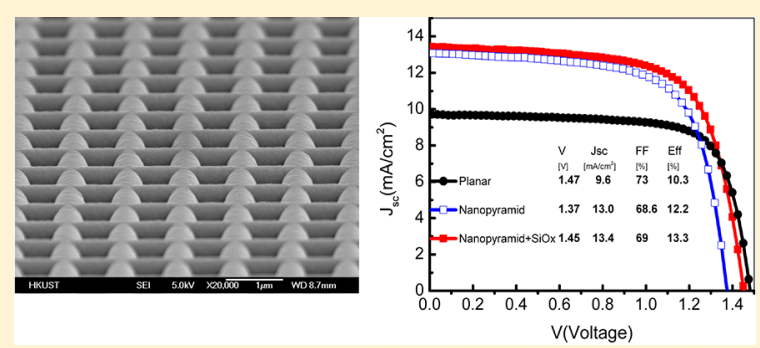
bottom cells, respectively. Meanwhile, the use of $\mathrm{SiO}_{x}$ mixed-phase nanomaterial helps to provide the maximum light trapping without paying the price of reduced electrical performance, and conversion efficiencies of up to $13.3 \%$ have been achieved for the ultrathin tandem cell employing only $8 \mu \mathrm{m}$ of silicon, which is $29 \%$ higher than the result obtained for the planar cell.

KEYWORDS: Ultrathin crystalline silicon, tandem cell, nanopyramid, nanomaterial, light trapping

$\mathrm{T}$ here is a strong cost drive to use ultrathin silicon solar cells with an active layer thickness of a few micrometers. ${ }^{1,2}$ A thinner layer has the added advantage of efficient charge carrier diffusion and collection due to the short collection length for photogenerated carriers, which creates the possibility for the utilization of low quality materials. Furthermore, ultrathin solar cells can be fabricated on a variety of low-cost and lightweight flexible substrates, such as glass, stainless steel, and plastic. However, thin film solar cell materials, especially the ultrathin crystalline silicon (c-Si), cannot effectively absorb light as the c-Si has a relatively low absorption coefficient on a broad spectrum, and therefore, ${ }^{3}$ advanced light trapping schemes are essential to achieve high efficiencies. ${ }^{4}$ At present, A very successful use of the light trapping scheme in silicon solar cells is the pyramid structure, which has a characteristic feature size of, typically, 3-10 $\mu \mathrm{m}$, larger than the thickness of thin film solar cells and can only be applied to bulk silicon solar cells. ${ }^{5}$ This imposes the limitation of the usage of microscale pyramid in ultrathin solar cells. However, nanoscale periodic texturing such as the nanowires, nanoholes, nanocones, and nanoparticles, with the feature size comparable to the wavelength of the desired spectral range, have recently been demonstrated in thin film solar cells to enhance light harvesting. $^{6-9}$

Such nanoscale light trapping schemes have successfully shown great promise to enhance the light absorption in singlejunction solar cells, but the conversion efficiencies of the solar cells are often improved only marginally as the parasitic loss of the electrical properties occurs on textured morphology. ${ }^{10-12}$ The challenge with these nanostructures is to maximize light absorption while mitigating electrical loss by removing the undesired local current drains in the device. ${ }^{13}$ Meanwhile, these light trapping schemes were mainly applied to single-junction solar cells; for multijunction cells that have been attempted in many forms for improving the solar cell efficiency beyond that of a single-junction solar cell, ${ }^{14,15}$ sophisticated studies of the light coupling in subcells are required and even necessary.

In this letter, we propose an ultrathin a-Si/c-Si tandem solar cell with enhanced light trapping scheme based on a nanopyramid structure at the interface of the top and bottom cells. Compared to the previously reported nanostructure in single-junction III-V solar cells, ${ }^{16}$ the aim of the nanopyramid is to be used in the ultrathin c-Si tandem cell. Because of the geometrical nature that allows for better conformal surface coverage, the top cell has a double-sided pattern with the nanopyramid; thus, it can provide excellent light confinement for the top and bottom cells simultaneously. Additionally, the use of the $\mathrm{SiO}_{x}$ nanomaterial provides a route for maximum light trapping without degrading the electrical performance of the cells, therefore allowing for high efficiency gains of ultrathin c-Si tandem cells employing only $8 \mu \mathrm{m}$ of silicon.

The fabrication process of the inverted nanopyramid structure is quite simple, scalable, and cost-effective, consisting of two main steps illustrated in Figure 1: an ultraviolet nanoimprint lithography (UV-NIL) ${ }^{17}$ step to replicate prepatterned 3D grating from the master in combination with a silicon anisotropic etching step to form the inverted pyramid structure. This approach can be easily repeatable and suitable for large scale production. Once the inverted nanopyramids are fabricated, a $12 \mathrm{~nm} \mathrm{p-a-Si} \mathrm{emitter} \mathrm{is} \mathrm{deposited} \mathrm{on} \mathrm{the} \mathrm{c-Si}$

Received: January 29, 2014

Revised: April 6, 2014

Published: April 14, 2014 
Glass Al Si SiO2 PMMA MSS4 a-Si

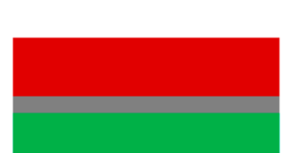

(a)

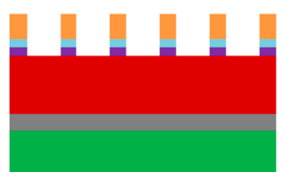

(d)

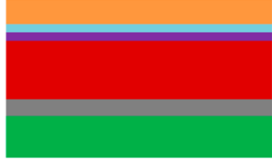

(b)

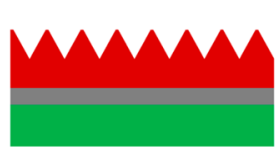

(e)

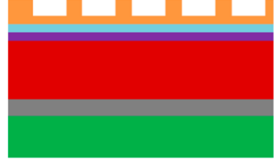

(c)

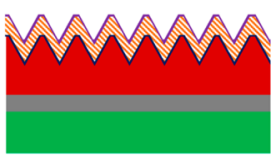

(f)
Figure 1. Schematic illustration of nanopyramid tandem cell fabrication. (a) The $8 \mu \mathrm{m}$ ultrathin c-Si on glass; (b) c-Si thin film coated with $\mathrm{SiO}_{2}, \mathrm{PMMA}$, and MSS4; (c) ultraviolet nanoimprint lithography (UV-NIL) applied to replicate the 3D grating from the master to the $\mathrm{c}-\mathrm{Si}$; (d) reactive ion etching used to remove the thin films on the c-Si surface; (e) after the PMMA lift-off, TMAH anisotropic etching was used to produce the inverted nanopyramid structure on the ultrathin c-Si surface; (f) the $12 \mathrm{~nm}$ p-a-Si emitter, 75 $\mathrm{nm}$ interlayer, $300 \mathrm{~nm}$ a-Si top cell, and $75 \mathrm{~nm}$ ARC conformally deposited on the ultrathin c-Si surface to form a tandem cell.

surface to form the heterojunction bottom cell, followed by a $75 \mathrm{~nm}$ sputtering $\mathrm{ZnO}: \mathrm{Al} / \mathrm{ITO}$ intermediate layer used to partially reflect the light back into the top cell to enhance the light absorption of the top cell, a $300 \mathrm{~nm} \mathrm{n-i-p} \mathrm{a-Si} \mathrm{top} \mathrm{cell} \mathrm{and}$ a $75 \mathrm{~nm}$ ITO antireflective coating layer finish the a-Si/c-Si tandem solar cell fabrication. More details on the fabrication processes are given in the methods section of the Supporting Information.

Figure 2a shows the photograph of the ultrathin a-Si/c-Si tandem solar cell with a nanopyramid structure. The size of the sample is $2 \mathrm{~cm} \times 2 \mathrm{~cm}$, which is limited by the master fabricated using the stepper lithography. The iridescent color gradient of the sample from the photograph is caused by the light interacting with the periodic subwavelength structure at
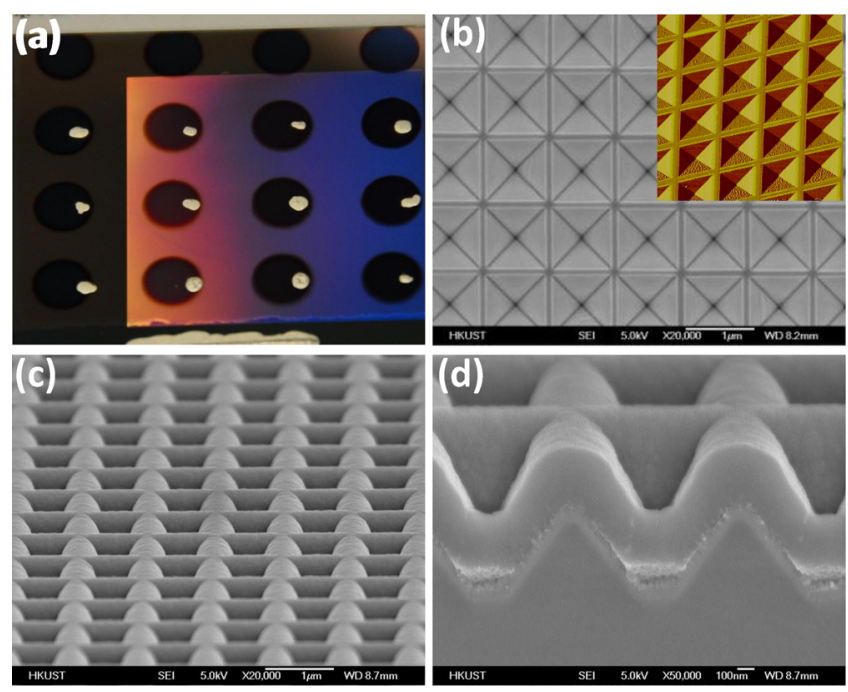

Figure 2. (a) Photograph of the ultrathin a-Si/c-Si tandem solar cell on glass; (b) top view SEM and AFM (insert) images of as-patterned inverted nanopyramids on the $8 \mu \mathrm{m}$ c-Si thin film; (c,d) $75^{\circ} \mathrm{SEM}$ of the ultrathin a-Si/c-Si tandem solar cell on the top surface and at the cross section. different angles. The top view scanning electron microscope (SEM) and atomic force microscopy (AFM) images of the resulting periodic inverted pyramid structure on an $8 \mu \mathrm{m} \mathrm{c}-\mathrm{Si}$ thin film surface are also shown in Figure $2 b$. As can been seen from these images, an inverted pyramid structure with a period of $1 \mu \mathrm{m}$ is obtained. The spacing between the adjacent pyramids can be controllable by a poststep that uses buffered oxide etch (BOE) to laterally etch the $\mathrm{SiO}_{2}$ after the reactive ion etching step, and $0-200 \mathrm{~nm}$ spacing can be obtained by varying the postetching time. The height of the nanopyramid can also be controlled approximately by the anisotropic wet etching time.

Unlike the nanopillar structure, which has a vertical morphology leading to pronounced deviations from conformality of the silicon layers, ${ }^{18}$ the angle of inclination of the inverted pyramid is suitable for the conformal growth of the subsequential films. As shown clearly in Figure $2 c$,d, when the $75 \mathrm{~nm}$ interlayer and $300 \mathrm{~nm}$ a-Si top cell are conformally deposited on the nanpopyramid structure of the c-Si bottom cell, the surface morphology of the device will inherit the nanostructure with a little lack of fidelity. As a result, in the ultrathin a-Si/c-Si tandem solar cell, the top surface of the device follows the nanopyramid geometry, which makes the top cell a double-sided structure with nanopyramids. This doublesided pattern is the key to achieve significant light trapping not only for the top cell but also for the bottom cell. Furthermore, it has been reported that the spacing between the adjacent pyramids is important for successful pattern transferring, ${ }^{19}$ but in our case, such an effect is not observed, even though the spacing is totally removed.

In order to get direct insights into the light trapping properties of the nanopyramids for the ultrathin a-Si/c-Si tandem solar cell, numerical simulation using the finitedifference time-domain (FDTD) method is performed to find out the spatial distribution of the carrier generation rate for the device. The standard nanopyramidal tandem cell illustrated here employs a Glass/Al $(250 \mathrm{~nm}) / \mathrm{n}^{+}-\mathrm{Si}(0.5 \mu \mathrm{m}) / \mathrm{c}-\mathrm{Si}$ absorber $(8 \mu \mathrm{m}) / \mathrm{p}$-a-Si emitter $(12 \mathrm{~nm}) /$ interlayer $(\mathrm{ZnO}: \mathrm{Al}+$ ITO, $75 \mathrm{~nm}) / \mathrm{n}$-i-p a-Si cell $(300 \mathrm{~nm}) /$ ITO $(75 \mathrm{~nm})$ structure. It should be noted that the spatial generation rate profile is integrating over all wavelengths, normalized by the AM1.5 spectral. Compared to the planar cell (Figure 3b), it can be observed that the tandem cell with nanopyramid structure demonstrates significant light absorption enhancement, not only in the a-Si top cell but also in the c-Si bottom cell (Figure $3 a)$. First, it is noted that the color index represents the generation rate. Tandem cell with nanopyramid structure exhibits a pronounced carrier generation rate throughout the a$\mathrm{Si}$ top cell, while the enhanced region is only concentrated near the surface of the top cell $(0-150 \mathrm{~nm})$ in the planar cell. Meanwhile, the highest value for the generation rate is $1.53 \times$ $10^{28}\left(1 \mathrm{~m}^{3} / \mathrm{s}\right)$, which is 3 times that of the planar structure. Second, the enhanced generation rate region extends from the top surface of the c-Si bottom cell to the position near $Z=-3$ $\mu \mathrm{m}$ in the case of the cell with nanopyramids, whereas such enhancement cannot be observed in the planar cell.

To further elucidate the light trapping effect of the nanopyramid structure on the top and bottom cells, respectively, the light absorption spectra for four different structures are calculated as shown in Figure 4a. The doublesided structure is the same as that of the real cell, whereas the front-only and the back-only are constructed, in which the texture are only realized at the front surface and back surface of 

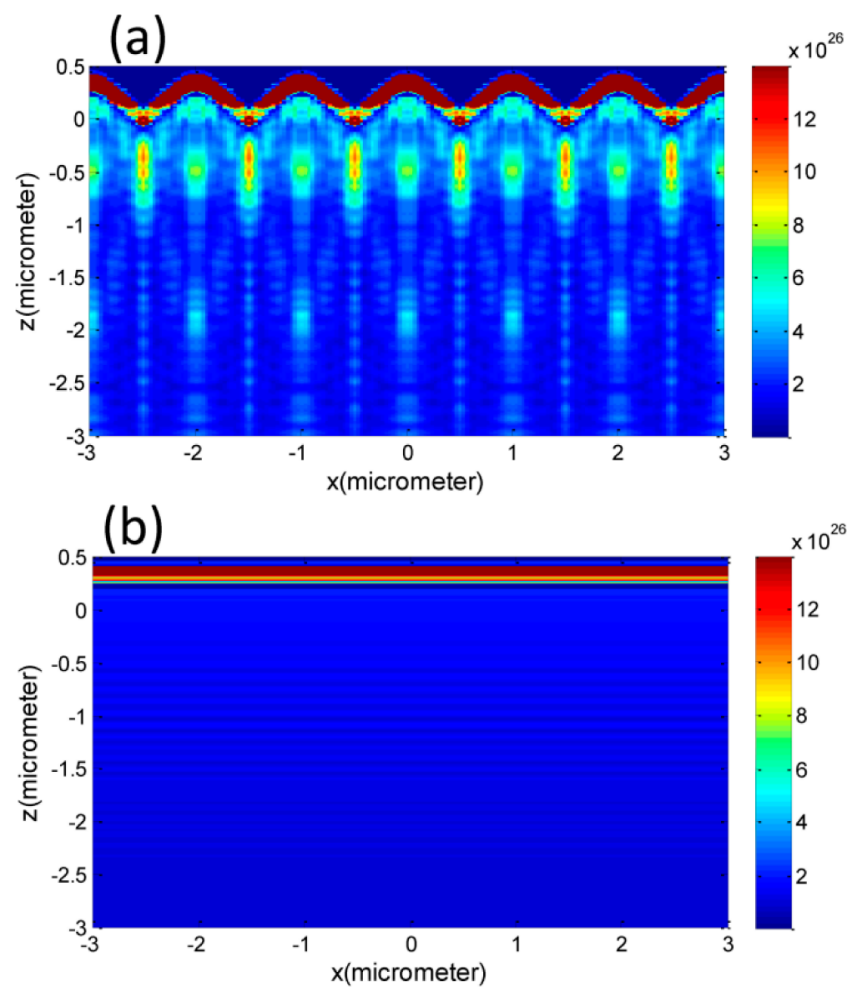

Figure 3. Spatial distribution of the carrier generation rates of the 8 $\mu \mathrm{m}$ ultrathin $\mathrm{a}-\mathrm{Si} / \mathrm{c}-\mathrm{Si}$ tandem solar cell with (a) nanopyramid structure and (b) planar structure. The thickness of the c-Si is only limited to $3 \mu \mathrm{m}$ in the figures.

the top cell, respectively, while ensuring the top cells always consist of the same amount of amorphous silicon as the planar cell or double-sided cell with predetermined thickness. The more details of the four structures are given in the simulation section of Supporting Information.

The front-only structure cell shows a largely broadband light absorption enhancement compared to the planar cell since the front side structure provides a gradual change of refractive index from the air to the a-Si at the top surface, which can be seen by the incoming light as an effective averaged index. Such an antireflection (AR) effect is broadband since the effective average index is independent of the light wavelength. In addition, the suppression of the reflection is especially remarkable at the short wavelength because the absorption depth is limited to tens of nanometers as a result of the high absorption coefficient at the short wavelength. At long wavelength, near $1000 \mathrm{~nm}$, the feature size array plays an important role for the enhancement of the light absorption in the bottom cell by coupling the diffraction order propagating outside the escape cone of the device. ${ }^{20}$

The light absorption behavior of the back-only structure cell is unexpected that the absorption of top cell is lower than in the planar cell, while the absorption of the bottom cell is greatly enlarged. Two key elements contribute to this situation. The first is that the back-only structure does not certainly contribute to the antireflection because there is no texturing at the top surface where light comes in. Furthermore, as we know, the loss fraction of rays at an interface is equal to $\left(n_{1}^{2} / n_{2}^{2}\right)$ when the interface is randomized. Here $n_{1}$ is the refractive index of c-Si and $n_{2}$ is the refractive index of a-Si in our case. As the back surface of the top cell is nanoscale pyramidally textured, which can be simply considered as randomization, the light escaping from the back surface of top cell into the bottom cell will probably be enlarged. In addition, the enhancement at the long wavelength near $1000 \mathrm{~nm}$ may be due to the guiding mode
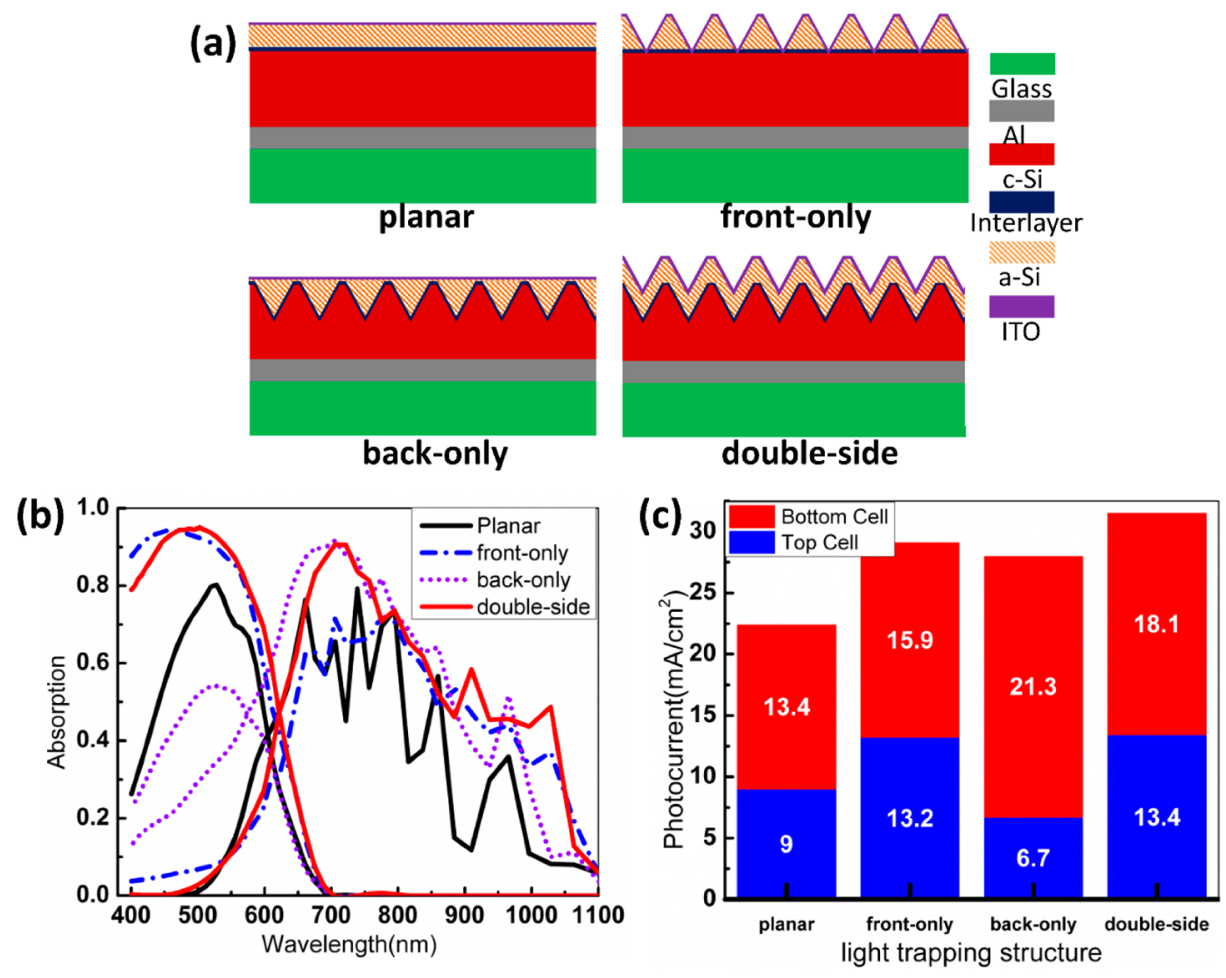

Figure 4. (a) Four tandem cell structures: planar, front-only, back-only, and double-sided; (b) absorption spectra for the cells; (c) photocurrent density for different cells. 
arising from the diffractive interlayer between the top cell and the bottom cell.

A striking difference between the results of different cells is that the double-sided cell, which is the combination of the front-only and back-only structure properties, provides the best performance not only for the top cell but also for the bottom cell among all the structures investigated. In the top cell, although the back-only geometry lowers the absorption, the double-sided cell still exhibits the largest absorption over the other cells. This may be ascribed to two major causes: the different geometries between the double-sided cell and the single-sided cells (front-only cell and back-only cell) and the enhanced total internal reflection. The first cause is obvious in that the single-sided cells are reconstructed to ensure that the top cells always consist of the same amount of amorphous silicon as the double-sided cell with predetermined thickness; the second cause is that the double-sided nanoscale structure prevents the escaping of a significant proportion of the rays after only two paths, which also occurs in the microscale double-sided pyramid structure $\mathrm{c}-\mathrm{Si}$ cell $^{21}$ and micromorph tandem cell with asymmetric intermediate reflector, ${ }^{22}$ in which case the light trapping properties of the double-sided patterning are virtually insensitive to the shape of the geometrical features. $^{21}$ This merit, giving a greatly reduced geometrical dependence, is particularly important from the point view of mass fabrication. In the bottom cell, the light trapping enhancement comes from the contribution of the top surface antireflection due to the top surface texturing $(400-1100 \mathrm{~nm})$, the diffraction enhancement of the nanostructure (near 1000 $\mathrm{nm}$ ), and the enlarged coupling from the top cell into the bottom cell because of the texturing of the intermediate layer (500-800 nm). These effects are clearly shown in Figure 5. In the planar cell, only specular reflections occur on the interlayer, and therefore, the enhancement in top cell is only twice. An interference pattern due to reflection at the interface is clear for the entire wavelengths in the bottom cell, while these patterns disappear in the double-sided nanostructure cell. Besides this, the excitation of the guided mode within the nanostructure also contributes to the light confinement in the bottom cell.

In terms of the short-circuit current possible from the cells with different light trapping schemes, the double-sided nanopyramidal cell provides the highest values for the top and bottom cells, which are $48 \%$ and $35 \%$ absolute gain compared to the planar cell (Figure $4 \mathrm{~b}$ ). Meanwhile, the total photocurrent of the double-sided cell is $31.5 \mathrm{~mA} / \mathrm{cm}^{2}$, while it is only $22.4 \mathrm{~mA} / \mathrm{cm}^{2}$ for the planar cell; this means an improvement of $40 \%$ is achieved. It also should be noted that the $31.5 \mathrm{~mA} / \mathrm{cm}^{2}$ photocurrent is even higher than that of the very successful commercialized micromorph tandem cell, the highest photocurrent of which is $28.3 \mathrm{~mA} / \mathrm{cm}^{2}{ }^{23}$

Although the nanopyramid light trapping scheme can largely improve the light absorption, the device is accompanied by a loss in the $V_{\text {oc }}$ particularly relevant to the difference between top cell deposition on flat and nanopyramidal surfaces. The performance of the top cell on different morphologies is shown in Table 1. One first notices that the standard nanopyramidal cell, which has $\mathrm{n}-\mu \mathrm{c}-\mathrm{Si}$ and $\mathrm{p}-\mathrm{a}-\mathrm{SiC}$ as the doped layers in the top cell, suffers from pronounced loss in $V_{\text {oc }}$. The reason, which is widely reported, is attributed to the increased local creation of defective material such as crack or porous area when deposited on highly textured morphology. ${ }^{24,25}$ In order to mitigate the parasitic loss of the electrical performance, advanced $\mathrm{SiO}_{x}$ nanomaterial is used as the doped layers for
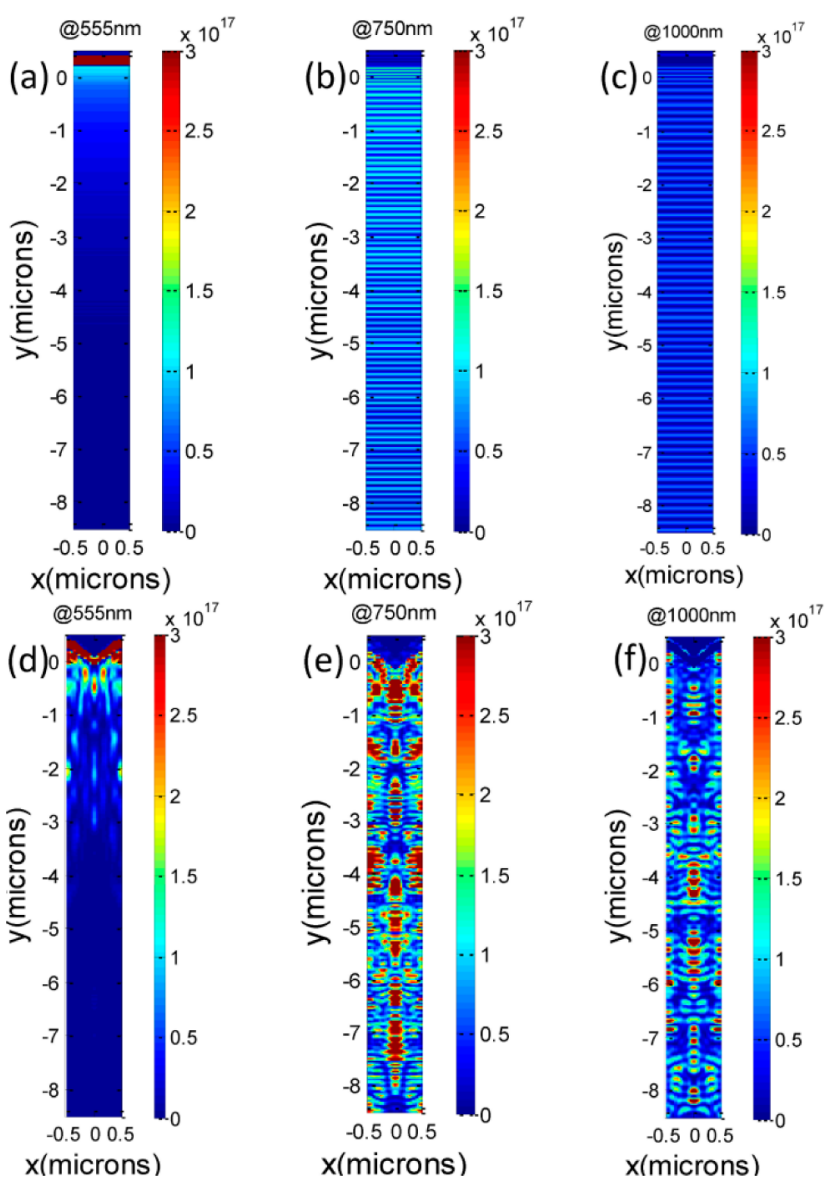

Figure 5. Spatial absorption profile for planar cell at (a) $550 \mathrm{~nm}$, (b) $750 \mathrm{~nm}$, and (c) $1000 \mathrm{~nm}$; spatial absorption profile for nanopyramid cell at (d) $550 \mathrm{~nm},(\mathrm{e}) 750 \mathrm{~nm}$, and (f) $1000 \mathrm{~nm}$.

Table 1. Characteristics of the top Cells with different doped layers and structures

\begin{tabular}{lccc}
\multicolumn{1}{c}{ top cell (structure) } & $V_{\mathrm{oc}}(\mathrm{V})$ & $F F(\%)$ & $J_{\mathrm{sc}}\left(\mathrm{mA} / \mathrm{cm}^{2}\right)$ \\
flat (planar) & 0.907 & 61 & 9.9 \\
standard (nanopyramid) & 0.842 & 56.8 & 13.4 \\
p-SiOx (nanopyramid) & 0.874 & 59 & 13.4 \\
p-SiOx + n-SiOx (nanopyramid) & 0.891 & 58.7 & 13.3 \\
\hline
\end{tabular}

the top cell. With the replacement of $\mathrm{p}-\mathrm{a}-\mathrm{SiC}$ by the mixedphase $\mathrm{p}-\mathrm{SiO}_{x}$, the $V_{\text {oc }}$ increases to $874 \mathrm{mV}$; it continues to reach $891 \mathrm{mV}$ when a resistive $\mathrm{n}-\mathrm{SiO}_{x}$ is further inserted between the $\mathrm{n}-\mu \mathrm{c}-\mathrm{Si}$ and intrinsic amorphous silicon layer, leaving only 16 $\mathrm{mV}$ loss in $V_{\text {oc }}$. Because the top cells are measured with the 75 $\mathrm{nm} \mathrm{ZnO}: \mathrm{Al} / \mathrm{ITO}$ interlayer as the back contact, the FF of these cells are limited by the high series resistance resulting from the low conductivity of the $75 \mathrm{~nm}$ interlayer, so there is little influence on the FF when $\mathrm{SiO}_{x}$ is used.

Dark $J V$ is measured to investigate the effort of the $\mathrm{SiO}_{x}$ doped layers on the performance of top cell. The saturation current $\left(j_{0}\right)$ and the diode factor $(n)$ are fitted as shown in Figure $6{ }^{26}$ The use of $\mathrm{SiO}_{x}$ as the doped layers in the device can effectively lower the $j_{0}$. The $n$ for the cell having the $\mathrm{n}-\mathrm{SiO}_{x}$ is reduced toward the interface recombination, while the $n$ for the cell with the $\mathrm{p}-\mathrm{SiO}_{x}$ only is not changed. So the insertion of the $\mathrm{n}$-SiOx results in the improvement of the intrinsic material properties, and the introduction of the $\mathrm{p}-\mathrm{SiO}_{x}$ only contributes to the interface improvement, which is consist with the recent 

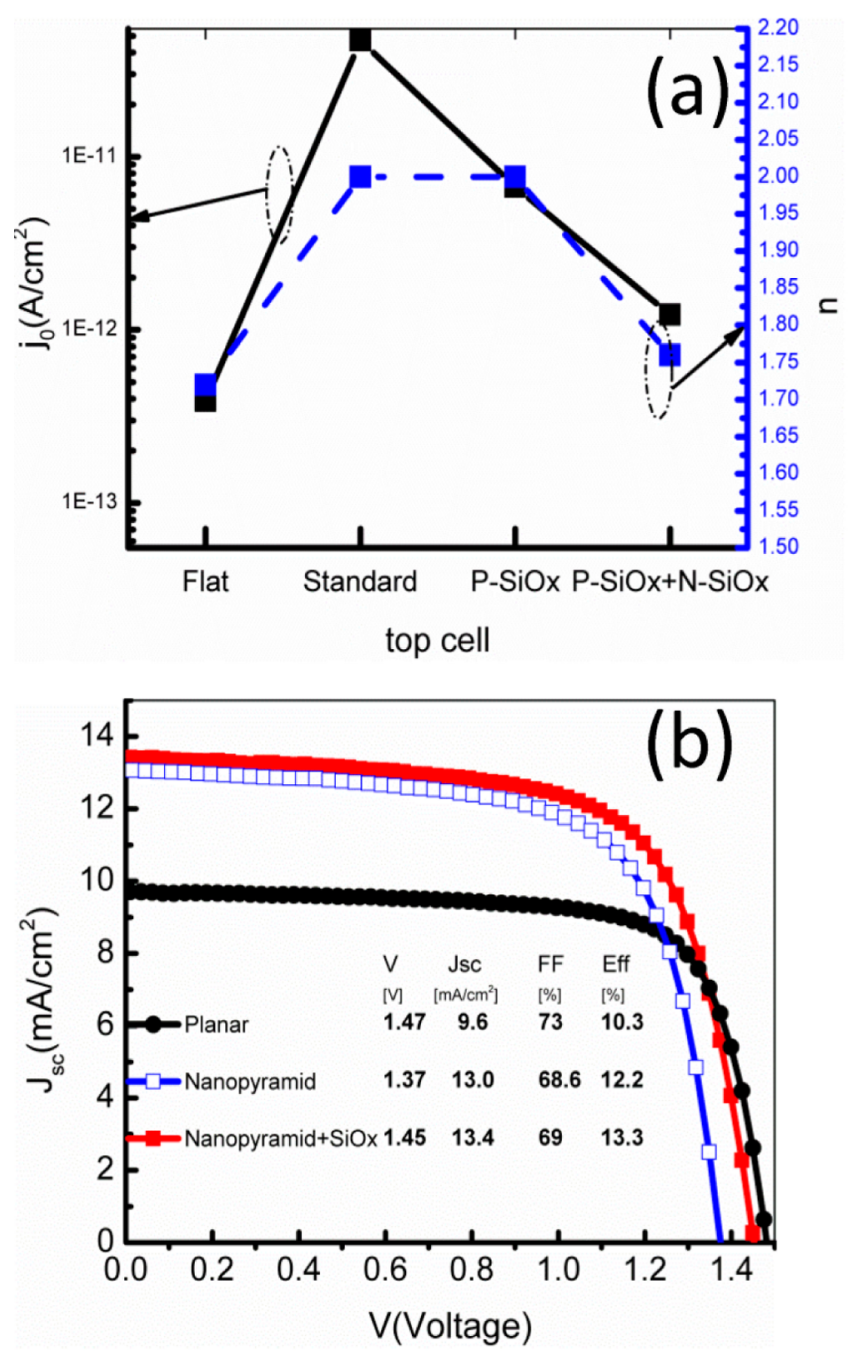

Figure 6. (a) $j_{0}$ and $n$ fitted from the dark $J V$; (b) $J-V$ curves of the planar, nanopyramid, and nanopyramid plus $\mathrm{SiO}_{x}$ ultrathin c-Si tandem cells.

result. ${ }^{27}$ As we know $\mathrm{SiO}_{x}$ is a mixed-phased nanomaterial consisting of nanometer silicon wire embedded in silicon oxide phase, ${ }^{28}$ it has a strong electrical anisotropy that the transverse conductivity is expected to be larger than the lateral conductivity; the low lateral conductivity helps to quench the undesired local current drains at the interface or in the intrinsic layer, while the high transverse conductivity maintains the low series resistance. ${ }^{29}$

The absolute increase in $V_{\text {oc }}$ and $J_{\text {sc }}$ lead to a dramatic improvement of the tandem cell efficiency. Compared to the planar cell without nanopyramid light trapping schemes, conversion efficiencies of up to $13.3 \%$ can be obtained, which is about $29 \%$ higher than the result obtained for the planar cell and $9 \%$ higher than that of the standard nanopyramidal cell (Figure 6b). The external quantum efficiency (EQE) of the $13.3 \%$ efficiency tandem cell was also measured and compared with the simulated absorption spectra (Figure 7). Red and green bias light was used during the measurement of the top and bottom cells, respectively. It should be noted that there is no consideration of the recombination loss for the simulated spectra. The $J_{\mathrm{sc}}$ of the top and bottom cells are 13.2 and 14.5 $\mathrm{mA} / \mathrm{cm}^{2}$, respectively, which are integrated from the measured EQE using AM1.5 $\mathrm{g}$ as the spectrum. The $J_{\mathrm{sc}}$ of the top and

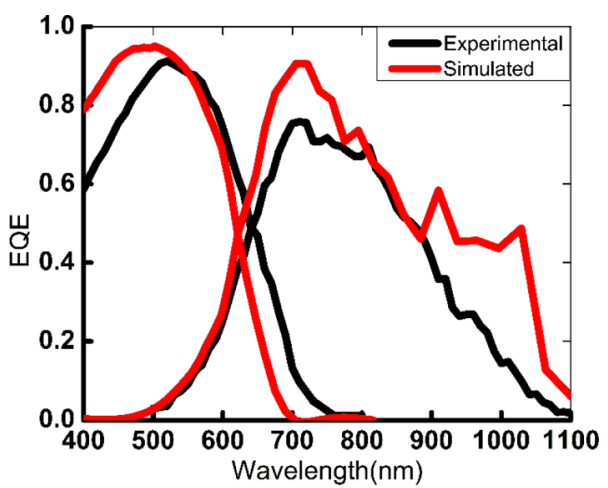

Figure 7. Simulated spectra and experimental External quantum efficiency of the $13.3 \%$ tandem cell.

bottom cells from the experimental results is slightly lower than that of the simulated results. The difference of the EQE (top cell) at the short wavelength $(<500 \mathrm{~nm})$ between the experimental and simulated results may result from the extra parasitic absorption of the ITO and p-type window layer, as well as the different top surface morphologies between the real device and the simulated structure, which have been discussed above. The EQE of the bottom cell shows quite similar except at the long wavelength $(900-1100 \mathrm{~nm})$, which may due to the recombination loss at the rear side of the bottom cell, where there is no passivation at the interface of the $\mathrm{n}+$ silicon and $\mathrm{Al}$ back contact. In fact, we did not perform any interface passivation of the ultrathin c-Si bottom cell, which are known to be important for the FF; and it also should be noted that the $J_{\mathrm{sc}}$ of the $8 \mu \mathrm{m} \mathrm{c}$-Si bottom cell is not the limitation, provided that the $J_{\text {sc }}$ of the top cell is further improved; state-of-the-art efficiency above $15 \%$ can be achieved in the ultrathin c-Si tandem cell.

In conclusion, we have demonstrated an $8 \mu \mathrm{m}$ ultrathin a-Si/ c-Si tandem solar cell on glass using a nanopyramid architecture as the efficient light trapping scheme. We achieve efficiencies of $13.3 \%$ for the ultrathin tandem cell, which is $29 \%$ higher than the planar cell. On the basis of our simulation and experimental study, we show that the double-sided property of the nanopyramid structure offers broadband light trapping for the tandem cell, leading to both increased short-circuit current of the top and bottom cells. The light absorption enhancement is not only coming from the guided mode due to the interacting of the photons and subwavelength structure but also resulting from the inherited front nanopyramidal surface, which provides an antireflection effect for the top and bottom cells simultaneously. Furthermore, $\mathrm{SiO}_{x}$ nanomaterial provides an unprecedented possibility to maximize the light trapping gain without loss in electrical performance of the cell. Our work suggests a viable path toward high-efficiency ultrathin $c-S i$ tandem solar cells for the further.

\section{ASSOCIATED CONTENT}

S Supporting Information

Methods, device characterization, dark $J V$ measurement, and simulation. This material is available free of charge via the Internet at http://pubs.acs.org.

\section{AUTHOR INFORMATION}

\section{Corresponding Author}

*(G.L.) E-mail: gliad@ust.hk. 


\section{Notes}

The authors declare no competing financial interest.

\section{ACKNOWLEDGMENTS}

This work was supported by the Innovation and Technology Commission of Hong Kong Government under Grant no. GHP/058/09SZ.

\section{REFERENCES}

(1) Wang, S.; Weil, B. D.; Li, Y.; Wang, K. X.; Garnnet, E.; Fan, S.; Cui, Y. Nano Lett. 2013, 13, 4393-4398.

(2) Yoon, J.; et al. Nat. Mater. 2008, 7, 907-915.

(3) Green, M. A. High Efficiency Silicon Solar Cells; Trans Tech Publications: Durnten-Zurich, Switzerland,1987.

(4) Tiedje, T.; Abeles, B.; Cebulka, J. M.; Pelz, J. Appl. Phys. Lett. 1983, 42, 712-714.

(5) Campbell, P.; Green, M. A. Sol. Energy Mater. Sol. Cells 2001, 65, 369-375.

(6) Garnett, E.; Yang, P. Nano Lett. 2010, 10, 1082-1087.

(7) Han, S. E.; Chen, G. Nano Lett. 2010, 10, 1012-1015.

(8) Wang, K. X.; Yu, Z.; Liu, V.; Cui, Y.; Fan, S. Nano Lett. 2012, 12, 1616-1619.

(9) Tan, H.; Santbergen, R.; Smets, A. H. M.; Zeman, M. Nano Lett. 2012, 12, 4070-4076.

(10) Garnett, E. C.; Yang, P. J. Am. Chem. Soc. 2008, 130, 92249225.

(11) Sai, H.; Kanamori, K.; Kondo, M. Appl. Phys. Lett. 2011, 98, 113502.

(12) Malm, U.; Edoff, M. Prog. Photovoltaics. 2009, 17, 306-314.

(13) Despeisse, M.; Boccard, M.; Bugnon, G.; Cuony, P.; Soderstrom, T.; Parascandolo, G.; Stuckelberger, M.; Charriere, M.; Lofgren, L.; Battaglia, C.; Hanni, S.; Billet, A.; Meillaud, F.; Ballif, C. Proceedings of the 5th World Conference on Photovoltaic Energy Conversion, Valencia, Spain, 2010; p 2793.

(14) Bremner, S. P.; Levy, M. Y.; Honsberg, C. B. Prog. Photovoltaics. 2008, 16, 225-233.

(15) Meier, J.; et al. Proceedings of the 13th EC Photovoltaic Solar Energy Conference, Nice, France, 1995; pp1445-1450.

(16) Liang, D.; et al. Adv. Energy Mater. 2012, 2, 1254-1260.

(17) Battaglia, C.; Escarré, J.; Söderström, K.; Erni, L.; Ding, L.; Bugnon, G.; Billet, A.; Boccard, M.; Barraud, L.; Wolf, S. D.; et al. Nano Lett. 2011, 11, 661-665.

(18) Hsu, C. M.; Battaglia, C.; Pahud, C.; Ruan, Z.; Haug, F. J.; Fan, S.; Ballif, C.; Cui, Y. Adv. Energy Mater. 2012, 2, 628-633.

(19) Feltrin, A.; et al. Sol. Energy Mater. Sol. Cells 2013, 119, 217227.

(20) Chong, T. K.; Wilson, J.; Mokkapati, S.; Catchpole, K. R. J. Opt. 2012, 14, 024012 .

(21) Campbell, P.; Green, M. A. J. Appl. Phys. 1987, 62, 243-249.

(22) Soderstrom, T.; Haug, F.-J.; Niquille, X.; Terrazzoni, V.; Ballif, C. Appl. Phys. Lett. 2009, 94, 063501.

(23) Boccard, M.; et al. Nano Lett. 2012, 12, 1344-1348.

(24) XPython, M.; Sauvain, E. V.; Bailat, J.; Dominé, D.; Fesquet, L.; Shah, A.; Ballif, C. J. Non-Cryst. Solids 2008, 354, 2258-2262.

(25) Nakajima, A.; Ichikawa, M.; Sawada, T.; Yoshimi, M.; Yamamoto, K. Jpn. J. Appl. Phys. 2004, 43, 7296-7302.

(26) Rech, B.; Beneking, C.; Wieder, S.; Wagner, H. Proceeding of 14th European Photovoltaic Solar Energy Conference, Barcelona, Spain, 1997; p 574.

(27) Biron, R.; Pahud, C.; Haug, F.-J.; Escarre, J.; Soderstrom, K.; Ballif, C. J. Appl. Phys. 2011, 110, 124511.

(28) Cuony, P.; Alexander, D. T. L.; Perez-Wurfl, I.; Despeisse, M.; Bugnon, G.; Boccard, M.; Söderström, T.; Hessler-Wyser, A.; Hébert, C.; Ballif, C. Adv. Mater. 2012, 24, 1182-1186.

(29) Despeisse, M.; Bugnon, G.; Feltrin, A.; Stuckelberger, M.; Cuony, P.; Meillaud, F.; Billet, A.; Ballif, C. Appl. Phys. Lett. 2010, 96, 073507. 